\title{
Substratos e regulador vegetal no enraizamento de estacas de pitaya ${ }^{1}$
}

\author{
Substrates and plant growth regulator on the rooting of pitaya cuttings
}

\author{
Caio Márcio Guimarães Santos ${ }^{2 *}$, Reginaldo Conceição Cerqueira ${ }^{3}$, Luíza Maria Souza Fernandes ${ }^{3}$, Franco \\ Willian Novaes Dourado ${ }^{4}$ e Elizabeth Orika Ono ${ }^{5}$
}

\begin{abstract}
Resumo - A pitaya é uma cactácea originária das florestas tropicais americanas que produz frutos exóticos bem apreciados e comercializados, principalmente no continente asiático. Contudo, ainda é uma espécie vegetal que demanda informações técnicas de cultivo nas áreas agrícolas brasileiras, motivando pesquisas em várias áreas do conhecimento. Objetivou-se avaliar diferentes substratos no enraizamento de cladódios imersos e não imersos no regulador de crescimento, ácido naftalenacético (ANA), na formação e desenvolvimento inicial de raízes em estacas de Hylocereus undatus, resultando em mudas mais vigorosas e de melhor qualidade. O experimento foi conduzido sob ripado no Departamento de Produção Vegetal - setor de Horticultura da Faculdade de Ciências Agronômicas no campus de Botucatu - UNESP. O delineamento experimental foi o inteiramente aleatorizado em esquema fatorial 4 x 2 (substratos x condições) com quatro repetições. Após 60 dias da instalação do experimento foram avaliados: massa fresca e seca da parte aérea, massa fresca e seca das raízes e o comprimento da maior raiz. O crescimento e desenvolvimento radicular inicial de mudas não são influenciados pelo regulador vegetal ANA. Os substratos com a presença de areia são os mais adequados para a formação de mudas vigorosas e de boa qualidade. A mistura areia + esterco bovino proporciona maior acúmulo de fitomassa no sistema radicular de pitaya (H. undatus).
\end{abstract}

Palavras-chave - Cactácea. Estaquia. Raízes Adventícias.

\begin{abstract}
The pitaya, a cactaceous species native to American tropical forests, produces well-appreciated and commercialized exotic fruits, mainly in the Asian continent. However, this plant species still requires technical information regarding cultivation in Brazilian agricultural areas, encouraging thus studies in several knowledge areas. This work aimed to evaluate the effect of different substrates on the rooting of cladodes immersed or not in the plant growth regulator naphthaleneacetic acid (ANA), as well as on root formation and initial development of Hylocereus undatus cuttings, which provides more vigorous and higher-quality seedlings. The experiment was carried out in a lath house of the Department of Plant Production - Horticulture Sector, College of Agronomical Sciences, Botucatu Campus, São Paulo State University (UNESP). Experimental design was completely randomized, in a $4 \times 2$ (substrates $\mathrm{x}$ conditions) factorial arrangement, with four replicates. At 60 days after the experiment establishment, shoot fresh and dry matter, root fresh and dry matter, and the highest root length were evaluated. The initial root growth and development of seedlings were not influenced by ANA. Substrates containing sand were the most suitable to produce vigorous and high-quality seedlings. Sand+manure bovine mixture provided higher phytomass accumulation in the root system of pitaya (H. undatus).
\end{abstract}

Key words - Cactaceous. Cutting. Adventitious Roots.

\footnotetext{
* Autor para correspondência

${ }^{1}$ Recebido para publicação em 10/09/2009; aprovado em 15/09/2010

Pesquisa desenvolvida no curso de Pós-Graduação na área de Horticultura da Faculdade de Ciências Agronômicas/UNESP

${ }^{2}$ Departamento de Produção Vegetal, Faculdade de Ciências Agrárias/UNESP, Caixa Postal 237, Botucatu-SP, Brasil, 18.610-307, caio@fca.unesp.br

${ }^{3}$ Departamento de Produção Vegetal , Faculdade de Ciências Agrárias/UNESP, Caixa Postal 237, Botucatu-SP , Brasil, 18.610-307, reconcer@ yahoo.com.br, nandesf_mt@hotmail.com

${ }^{4}$ Área de concentração em Fitotecnia, Universidade Estadual da Bahia/UESB, Estrada do Bem-Querer, Km 04, Bairro Universitário, Vitória da

Conquista-BA, Brasil, 45.083-900, francodourado@yahoo.com.br

${ }^{5}$ Departamento de Botânica, IB/UNESP, Distrito de Rubião Junior, Caixa Postal 510, Botucatu-SP, Brasil, 18.618-000, eoono@ibb.unesp.br
} 


\section{Introdução}

A pitaya (Hylocereus undatus) é uma espécie vegetal trepadeira e frutífera, pertencente à família das cactáceas, e que vêm se destacando no mercado de frutas exóticas no Brasil.

Em seu habitat apresenta-se predominantemente como espécie de metabolismo CAM, embora sob condições de sombreamento tenham a capacidade de efetuar CAM cíclico, e devido à sua rusticidade, a pitaya torna-se uma alternativa com potencial agronômico, econômico (ORTIZ et al., 1999) e nutricional em terrenos rasos, arenosos e pedregosos. Sua propagação se dá pelo método convencional, por meio dos cladódios inteiros ou seccionados. O tamanho do cladódio é a característica mais importante quando se seleciona material para plantação, já que ele afetará a quantidade e o tamanho dos brotos produzidos durante o primeiro ciclo da plantação (FAO, 2001).

Diversos fatores influenciam o método de propagação da pitaya, tais como: genótipo, condições fisiológicas da planta-matriz, tipo de estaca e condições ambientais (FACHINELLO et al., 2005; FRANCO et al., 2007; PIO et al., 2006).

O processo de formação de raízes em estacas de plantas frutíferas é afetado por muitos fatores como: a variabilidade genética, o estado fisiológico da planta matriz, a idade da planta, o tipo de estaca, a época do ano, as condições ambientais e o substrato (NACHTIGAL; PEREIRA, 2000).

Para atender às necessidades das plantas, um substrato padrão, independente de sua composição, deve apresentar baixa densidade, teor adequado de nutrientes; elevada capacidade de troca catiônica boa capacidade de retenção de água (BRUXEL et al., 2002), aeração e drenagem, boa coesão entre as partículas e ser isento de fungos, nematóides e plantas daninhas (ANTUNES et al., 2002; SILVA et al., 2001; TOLEDO, 1992).

O substrato ideal para o enraizamento depende da espécie, do tipo de estaca, da época, do sistema de propagação, do custo e da disponibilidade de seus componentes, sendo o sistema radicular da pitaya fasciculado, ele absorve rapidamente, pequenos teores de elementos no solo (LE BELLEC et al., 2006). Em alguns casos, substratos diferentes são indicados para uma mesma espécie, porém em fase diferentes do desenvolvimento da cultura (OLIVEIRA et al., 2006).

$\mathrm{Na}$ produção de mudas de pitaya, a propagação assexuada é a mais importante do ponto de vista comercial, pois aumenta a precocidade e a uniformidade fenotípica dos pomares, mantendo o seu valor agronômico
(COSTA et al., 2007). Além disso, é importante a obtenção de mudas com bom desempenho reprodutivo, pois a má formação compromete todo o desenvolvimento da cultura, aumentando o ciclo e perdas na produção (ECHER et al., 2007).

Várias fases da formação radicular exibem extrema sensibilidade à auxina exógena e está correlacionada com a mudança na concentração endógena de auxina.

Auxinas sintéticas, tais como ácido indolbutírico (AIB) e ácido naftalenacético (ANA) mostram ser mais efetivas do que a AIA, uma auxina de ocorrência natural para o enraizamento (VIVANCO; FLORES, 2000).

A pitaya por ser uma espécie vegetal ainda pouco explorada nas áreas agrícolas brasileiras demanda informações técnicas de cultivo, motivando, portanto, pesquisas em várias áreas do conhecimento. Assim, procurou-se avaliar diferentes substratos no enraizamento de cladódios imersos e não imersos no regulador de crescimento, ácido naftalenacético (ANA), na formação e desenvolvimento inicial de raízes em estacas de Hylocereus undatus, resultando em mudas mais vigorosas e de melhor qualidade.

\section{Material e métodos}

Oexperimento foi conduzido noperíodo de setembro a novembro de 2008, sob ripado, no Departamento de Produção Vegetal - setor de Horticultura da Faculdade de Ciências Agronômicas no campus de Botucatu - UNESP.

As estacas foram padronizadas no tamanho de $40 \mathrm{~cm}$ em plantas matrizes com 18 anos de idade. Esses cladódios foram plantados a uma profundidade de $5 \mathrm{~cm}$ em sacos de polietileno furados com capacidade para 3L. A irrigação foi efetuada manualmente, sempre que necessária. $\mathrm{O}$ delineamento experimental utilizado foi o inteiramente aleatorizado com 4 repetições, em esquema fatorial $4 \times 2$, sendo: quatro substratos (areia, terra, areia + esterco e terra+esterco, sendo os tratamentos com esterco bovino na proporção $(3: 1)$ ) e duas condições (com e sem embebição na solução do regulador vegetal ANA).

A aplicação do regulador vegetal foi realizada mediante imersão dos cladódios em solução preparada de ANA na concentração de $200 \mathrm{mg} \mathrm{L}^{-1}$ por um período de 24 horas.

Após 60 dias da instalação do experimento foram avaliadas as seguintes características: massa fresca da parte aérea (MFPA) (g), massa seca da parte aérea (MSPA) (g), massa fresca de raiz (MFR) (g), massa seca de raiz (MSR) $(\mathrm{g})$ e comprimento da maior raiz $(\mathrm{CR})(\mathrm{cm})$. 
Os cladódios e as raízes foram lavados para retirar o substrato aderido e depois secos em estufa com circulação de ar forçada, em temperatura de $65{ }^{\circ} \mathrm{C}$ até a obtenção de peso constante, e em seguida pesados em balança de precisão. $\mathrm{O}$ comprimento da maior raiz por planta foi realizado com régua graduada, a partir da inserção da raiz na base do cladódio.

Após a coleta, os dados foram submetidos à análise de variância e as médias comparadas pelo teste de Tukey, ao nível de $5 \%$ de probabilidade, utilizando-se o software de análise estatística Sisvar® (FERREIRA, 2000).

\section{Resultados e discussão}

Observa-se nas Tabelas 1 e 2 que a imersão das estacas na solução com ANA não influenciaram diferenças significativas na massa fresca e seca de cladódios e raízes, e no comprimento da maior raiz. Dessa forma o nível endógeno de auxinas nas estacas pode ter suprimido a interferência da aplicação exógena no que tange ao estímulo do crescimento e desenvolvimento radicular inicial. Assim, o tamanho da estaca utilizada pode ter tido uma quantidade de reserva suficiente para o estímulo radicular sem a necessidade do uso exógeno do regulador vegetal ANA. Contrariamente, Althaus et al. (2007) estudando diferentes substratos no enraizamento de estacas de Jasmim-amarelo, com e sem a veiculação em talco de ácido naftaleno acético na concentração de $5000 \mathrm{mg} \mathrm{kg}^{-1}$ obteve resultados significativos e positivos para a variável comprimento das cinco maiores raízes, quando combinou o regulador com o substrato vermiculita.

Para Vargas-Santiago et al. (2003), o uso de reguladores vegetais antes do plantio fomenta rapidamente a formação de raízes, sendo que o número de raízes adventícias aumenta quando os cladódios de Hylocereus undatus são imersos em AIB na concentração de $10.000 \mathrm{mg} \mathrm{L}^{-1}$. Contudo, em função de termos utilizado outra fonte sintética de auxina e uma concentração inferior não foram observados tais resultados.

Os reguladores vegetais sintéticos do grupo das auxinas são substâncias que auxiliam no enraizamento de estacas. Porém, algumas espécies vegetais em função do tamanho, idade e a reserva de carboidratos presente nas estacas, tornam-se insensíveis ao efeito estimulante da auxina sintética, conforme observado neste estudo.

Tabela 1 - Resumo da análise de variância para as características massa fresca da parte aérea (MFPA), massa seca da parte aérea (MSPA), massa fresca de raízes (MFR) e massa seca de raízes (MSR) em cladódios de Pitaya (Hylocereus undatus). UNESP, Botucatu-SP, 2008

\begin{tabular}{cccccc}
\hline \multirow{2}{*}{ Fontes de Variação } & \multirow{2}{*}{ GL } & \multicolumn{4}{c}{ Quadrados Médios } \\
\cline { 3 - 6 } & & MFPA & MSPA & MFR & MSR \\
\hline Substrato & 3 & $25090,91 \mathrm{~ns}$ & $194,29 \mathrm{~ns}$ & $1683,17^{*}$ & $39,15^{*}$ \\
Regulador & 1 & $95,35 \mathrm{~ns}$ & $6,91 \mathrm{~ns}$ & $0,09 \mathrm{~ns}$ & $3,10 \mathrm{~ns}$ \\
Sub*Reg & 3 & $7631,48 \mathrm{~ns}$ & $408,74 \mathrm{~ns}$ & $3,03 \mathrm{~ns}$ & $2,14 \mathrm{~ns}$ \\
Resíduo & 24 & 1652028,82 & 108,48 & 19,18 & 0,88 \\
CV (\%) & & 46,37 & 32,97 & 44,97 & 51,11 \\
\hline
\end{tabular}

*significativo a $5 \%$ de probabilidade pelo teste de $\mathrm{F}$.; ns - não significativo a $5 \%$ de probabilidade pelo teste $\mathrm{F}$

Tabela 2 - Resumo da análise de variância para a característica comprimento da maior raiz (CR) em cladódios de Pitaya (Hylocereus undatus). UNESP, Botucatu-SP, 2008

\begin{tabular}{ccc}
\hline Fontes de Variação & GL & Quadrados Médios \\
\cline { 3 - 3 } & & CR \\
\hline Substrato & 3 & $294,648750^{*}$ \\
Regulador & 1 & $1,361250 \mathrm{~ns}$ \\
Sub*Reg & 3 & $13,098750 \mathrm{~ns}$ \\
Resíduo & 24 & 39,260208 \\
CV (\%) & & 57,85 \\
\hline
\end{tabular}

* significativo a 5\% de probabilidade pelo teste de $\mathrm{F}$; ns - não significativo a 5\% de probabilidade pelo teste $\mathrm{F}$ 
Não houve interação significativa entre os fatores estudados para nenhuma das variáveis analisadas. Contudo, o fator de variação substrato promoveu diferenças significativas nas características do sistema radicular dos cladódios (MFR, MSR e CR) (TAB. 1 e 2).

$\mathrm{O}$ uso de diferentes substratos influenciou a massa seca e fresca de raízes, diferindo em parte dos resultados encontrados por Silva et al. (2006), onde os mesmos não obtiveram influência de diferentes substratos, na massa seca de raízes, e sim na massa fresca para pitaya vermelha.

Nota-se na Tabela 3 que nos dois substratos testados que tiveram como base a areia em sua composição foram os que apresentaram os melhores desempenhos das características avaliadas, tendo destaque a composição areia+esterco que foi quatro vezes $(31,47 \mathrm{~g})$ superior a soma de todos os outros substratos juntos para a característica massa fresca, duas vezes $(5,15 \mathrm{~g})$ superior aos demais no quesito massa seca e apresentou um comprimento radicular bastante vigoroso, com o tamanho da maior raiz de aproximadamente, três vezes $(19,75 \mathrm{~cm})$ mais ao da combinação terra + esterco.

O grande diferencial em gramas entre os substratos, em relação às componentes MFR e MSR pode ser atribuído a um maior volume de raízes secundárias (Dados não apresentados) presentes no substrato areia + esterco, sendo essa uma característica desejável na formação de mudas, pois essas raízes proporcionarão maior área a ser explorada para absorver água e minerais presentes no substrato e, com isso, elas se adaptarão melhor quando transplantadas para o campo.

Para os tratamentos onde o substrato continha terra, todas as variáveis analisadas foram inferiores aos substratos com areia. E esse desempenho, relativamente superior em substratos com areia, em comparação aos com terra, pode ser atribuído à adaptação e ocorrência da espécie em locais com solos arenosos.

Gunasena et al. (2007) afirmam que a pitaya requer solos bem drenados, levemente ácidos e com bastante matéria orgânica. No presente trabalho, não houve um controle da quantidade de água fornecida, porém foi semelhante para todos os tratamentos. Isso pode ter contribuído em função das características físicoquímicas dos substratos, para um maior aproveitamento pelos cladódios no decorrer do desenvolvimento do sistema radicular nos tratamentos com areia, sendo a drenagem neste caso o fator limitante, pois a areia é rica em macroporos que drenam a água com facilidade, coisa que não acontece com a terra utilizada por ter uma maior quantidade de microporos favorecidos pela presença do colóide argila, retendo um maior volume de água que pode ter prejudicado a aeração do ambiente radicular. As propriedades físicas de um substrato são relativamente mais importantes que as químicas, devido a sua composição não ser facilmente modificada durante a formação das mudas.

Para Schaffer et al. (2005) a escolha do tipo de substrato é importante tanto para a propagação vegetativa quanto por sementes e constitui um dos fatores de maior influência no enraizamento de estacas, pois além de sustentá-las, mantém a base úmida, aerada e protegida da luz. Sendo que estes fatores podem variar em função do material utilizado (WAGNER JÚNIOR et al., 2006).

O substrato mais propício teria que ter características físico-químicas adequadas para um favorável crescimento e desenvolvimento radicular inicial dos cladódios, além de disponibilidade e baixo custo.

Assim, mais pesquisas são necessárias relacionando tempo de avaliação, substratos e diferentes concentrações e outras características não abordadas neste trabalho como: número de cladódios enraizados, número de cladódios com calos, número de brotações, comprimento médio das brotações, número médio de raízes.

Tabela 3 - Massa fresca de raízes (MFR), massa seca de raízes (MSR) e comprimento da maior raiz (CR) em cladódios de Pitaya (Hylocereus undatus). UNESP, Botucatu-SP, 2008

\begin{tabular}{lccc}
\hline \multicolumn{1}{c}{ Substratos } & MFR $(\mathrm{g})$ & MSR $(\mathrm{g})$ & CR $(\mathrm{cm})$ \\
\hline Areia & $3,36 \mathrm{~b}$ & $0,84 \mathrm{~b}$ & $9,51 \mathrm{~b}$ \\
Terra & $1,60 \mathrm{~b}$ & $0,54 \mathrm{~b}$ & $7,44 \mathrm{~b}$ \\
Areia + esterco & $31,47 \mathrm{a}$ & $5,15 \mathrm{a}$ & $19,75 \mathrm{a}$ \\
Terra + esterco & $2,53 \mathrm{~b}$ & $0,82 \mathrm{~b}$ & $6,62 \mathrm{~b}$ \\
\hline \multicolumn{1}{c}{ DMS } & 6,04 & 1,30 & 8,64 \\
\hline
\end{tabular}

Médias seguidas por mesma letra na coluna não diferem entre si pelo teste de Tukey a 5\% de probabilidade 


\section{Conclusões}

1. O crescimento e desenvolvimento radicular inicial de mudas de pitaya (Hylocereus undatus) não são influenciados pelo regulador vegetal ANA;

2. Substratos com a presença de areia são os mais adequados para a formação de mudas vigorosas e de boa qualidade;

3. A mistura areia+esterco bovino proporciona maior acúmulo de fitomassa no sistema radicular da pitaya (H. undatus).

\section{Referências}

ALTHAUS, M. M. et al. Influência do ácido naftaleno acético e dois tipos de substrato no enraizamento de estacas de jasmim-amarelo. Revista Ciência Agronômica, v. 38, n. 03, p. 322-326, 2007.

ANTUNES, L. E. C. et al. Tratamento de substratos na produção de mudas de plantas frutíferas. Informe Agropecuário, v. 23, n. 216, p. 16-20, 2002

BRUXEL, D. et al. Lâminas de irrigação e doses de um condicionador de solo para produção de mudas de tomateiro grupo agroindustrial. Horticultura Brasileira, v. 20, n. 02, p. 1317-1318, 2002.

COSTA, L. C. do B; PINTO, J. E. B. P.; BERTOLUCCI, S. K. V. Comprimento da estaca e tipo de substrato na propagação vegetativa de atroveran. Ciência Rural, v. 37, n. 04, p. 1157-1160, 2007

ECHER, M. de M. et al. Avaliação de mudas de beterraba em função do substrato e do tipo de bandeja. Ciências Agrárias, v. 28 , n. 01, p. 45-50, 2007.

FACHINELLO, J. C.; HOFFMANN, A.; NACHITIGAL, J. C. Propagação de plantas frutíferas. Brasília: Embrapa Informação Tecnológica, 2005. 221 p.

FERREIRA, D. F. Sistema de análise estatística para dados balanceados (SISVAR). Lavras: UFLA-DEX. 2000. 145 p.

FOOD AND AGRICULTURE ORGANIZATION OF THE UNITED NATIONS- FAO. Agroecologia cultivo e usos da palma forrageira Estudo da FAO em proteção e produção vegetal. Paraíba: SEBRAE/PB, p. 132-216, 2001.

FRANCO, D. et al. Estaquia como processo de clonagem do Bacuri (Redhia garderiana Miers ex Planch e Triana). Revista Brasileira de Fruticultura, v. 29, n. 01, p. 176-178, 2007.

GUNASENA, H. P. M.; PUSHPAKUMARA, D. K. N. G.; KARIYAWASAM, M. Dragon fruit (Hylocerus undatus (Haw.) Britton and Rose). In: PUSHPAKUMARA, D. K. N. G.;
GUNASENA, H. P. M.; SINGH, V. P. Underutilized fruit trees in Sri Lanka. World Agroforestry Centre, South Asia Office; New Delhi, India, 2007. cap. 4, p.110-142.

LE BELlEC, F.; VAILlANT, F.; IMBERT, E. Pitahaya (Hylocereus spp.): a new crop, a market with a future. Fruits, v. 61, n. 04 , p. 237-250, 2006.

NACHTIGAL， J. C.; PEREIRA， F. M. Propagação do pessegueiro (Prunus persica (L.) Batsch) cultivar Okinawa por meio de estacas herbáceas em câmara de nebulização. Revista Brasileira de Fruticultura, v. 22, n. 02, p. 208-212, 2000

OLIVEIRA, I. V. de M.; CAVALCANTE, I. H. L.; MARTINS, A. B. G. Influência do substrato na emergência de plântulas de sapota preta. Revista Caatinga, v. 19, n. 04, p. 383-386, 2006.

ORTIZ, Y. D. M. et al. Estrés hídrico y intercambio de CO2 de La pitahaya (Hylocereus undatus), Agrociencia, v. 33, p. 397-405, 1999

PIO, R. et al. Propagação de estacas apicais de figueira: diferentes ambientes, ácido indolbutírico e tipo de estaca. Ciência e Agrotecnologia, v. 30, n. 05, p. 1021-1026, 2006.

SCHAFFER, G. et al. Substrato na emergência de plântulas e expressão de poliembrionia em porta-enxerto de citros. Ciência Rural, v. 35, n. 02, p. 471-474, 2005.

SILVA, R. P. da; PEIXOTO, J. R.; JUNQUEIRA, N. T. V. Influência de diversos substratos no desenvolvimento de mudas de maracujazeiro azedo (Passiflora edulis Sims f. flavicarpa DEG). Revista Brasileira de Fruticultura, v. 23, n. 02, p. 377-381, 2001.

SILVA, M. T. H.; MARTINS, A. B. G.; ANDRADE, R. A. DE. Enraizamento de estacas de pitaya vermelha em diferentes substratos. Revista Caatinga, v. 19, n. 01, p. 61-64, 2006.

TOLEDO, A. R. M. Efeito dos substratos na formação de mudas de laranjeiras (Citrus sinenses (L.) Osbeck cv Pêra Rio) em vasos. 1992. 88 f. Dissertação (Mestrado em Fitotecnia), Escola Superior de Agricultura de Lavras, Lavras.

VARGAS-SANTIAGO, G. et al. Vegetative propagation of Hylocereus undatus and its relationship with substrate and IBA. Cactaceas-succulentas-Mexicanas, v. 48, n. 04, p. 111-117, 2003.

VIVANCO, J. M.; FLORES, H. C. Control of root formation by plant growth regulators. In: BARSA, A. J. (Ed) Plant growth regulators in agriculture and horticulture: their role and commercial uses. New York: Food Products Press, 2000. cap.1, p.1-16.

WAGNER JÚNIOR, A. et al. Influência do substrato na germinação e desenvolvimento inicial de plantas de maracujazeiro amarelo (Passiflora edulis sims f. flavicarpa deg). Ciência e Agrotecnologia, v. 30, n. 04, p. 643-647, 2006. 